\title{
The radio-based train control system ATACS
}

\author{
N. Miyaguchi, D. Uchiyama, I. Inada, Y. Baba \& N. Hiura \\ Department of Electrical \& Signal Network Systems, \\ East Japan Railway Company, Japan
}

\begin{abstract}
In traditional signalling systems, the train location is detected by the track circuit, and the train is controlled by wayside signaling equipment. Therefore, an enormous volume of ground equipment is required for track circuits, signals, level crossings, and so on. The equipment often breaks down because it is installed under unfavourable conditions such as areas prone to extreme temperature fluctuation or excess vibration. And acquisition cost and maintenance cost is high. To solve these problems, we developed and have been introducing a new train control system called "ATACS" (Advanced Train Administration and Communications System). ATACS is a radio-based train control system using information technology.

ATACS is equivalent to ERTMS/ETCS level 3 or CBTC. The ATACS train control method is fundamentally different from traditional signaling systems, because train position detection is determined by on-board equipment rather than by track circuits. Information transmission between the ground and the trains is conducted via digital radio communication, and the signal is displayed in the cab. ATACS is offering full moving block capability. With ATACS, an on-board computer calculates the train location and transmits it to the ground controllers, which continuously transmit Limit of Moving Authority (LMA) to each train based on the reported locations of all the trains on the network. The on-board computer calculates a parabolic braking profile based on the Limit of Moving Authority received from the ground controllers.

We put ATACS into commercial operation on the Senseki Line in October 2011. We have confirmed ATACS' stability over the last two years, so we are going to introduce ATACS on the Saikyo Line. This will be the first time it is implemented in the Tokyo metropolitan area.

In this paper, we outline ATACS and its operation after the commercial use on the Senseki Line, and plan to implement ATACS on the Saikyo Line.

Keywords: train control system, radio communications technology, train position detection, track circuit, moving block.
\end{abstract}




\section{Introduction}

\subsection{Background}

Traditionally, train detection functions and signal display functions are handled by many types of equipment installed along tracks. This equipment is prone to failure due to severe conditions such as extreme fluctuation in temperature or vibration, and are labor-intensive and costly to maintain. Moreover, such maintenance work can lead to labor accidents. Streamlining of wayside equipment has been required to mitigate these issues.

In contrast, ATACS mainly uses onboard devices to detect train position and wirelessly displays signals in the cab, thus reducing the need for wayside equipment.

\subsection{Advantage of ATACS}

There are three advantages in implementing ATACS.

- Improved of railway safety

- Staler transportation and cost reduction

- Improved follow-up to changes

\subsubsection{Improved railway safety}

On-board control equipment performs speed calculation profile continuously, and brakes if necessary. Therefore, excessive speed caused by human error can be prevented. In the event that an automobile stalled inside a level crossing is detected by the obstruction detection device, control is performed to stop the train before the crossing.

\subsubsection{Stabler transportation and cost reduction}

Massive and complicated wayside equipment such as conventional signal track circuits, ATS-related equipment and cables can be replaced by a radio system and one on-board control device. In this way, wayside equipment can be minimized [1]. Simplifying wayside equipment will reduce failure, therefore it leading stabilization of transportation and lower maintenance cost.

\subsubsection{Improved of follow-up to changes}

We can reduce the need for signal construction work when changing rail tracks, and rolling stock performance has also improved.

\section{Main features of ATACS}

ATACS performs interactive radio communications between wayside and onboard equipments. That allows wayside equipments to receive detailed train position information and onboard devices to incorporate and reflect routing information and safeguard information in real time. 
This enables the following:

- $\quad$ Efficient train interval control (moving block)

- More efficient test runs using actual cars

- Level crossing control by radio.

Fig. 1 shows comparison of conventional system and ATACS, and Fig. 2 shows an overview of train interval control by ATACS.
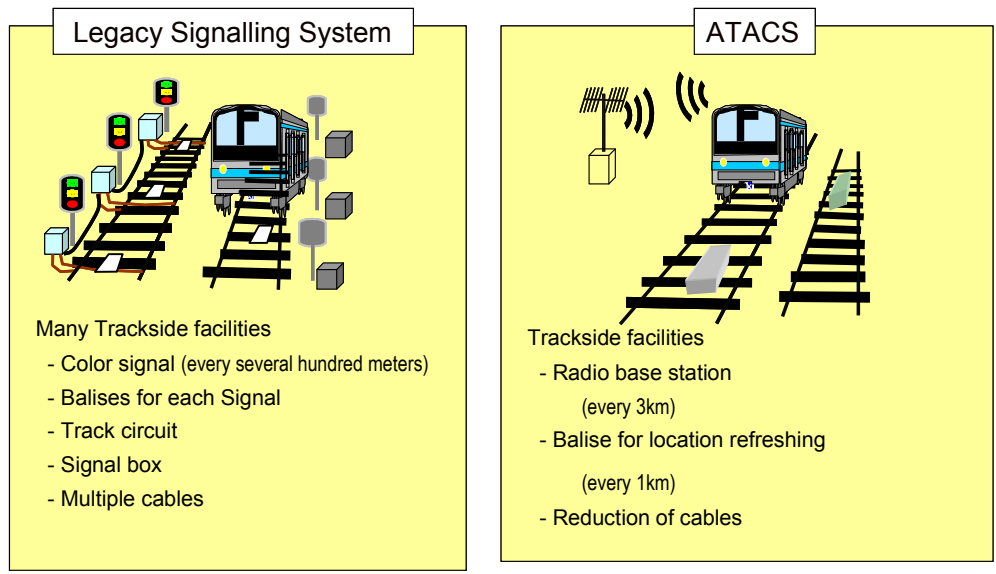

Figure 1: Comparison of conventional system and ATACS.

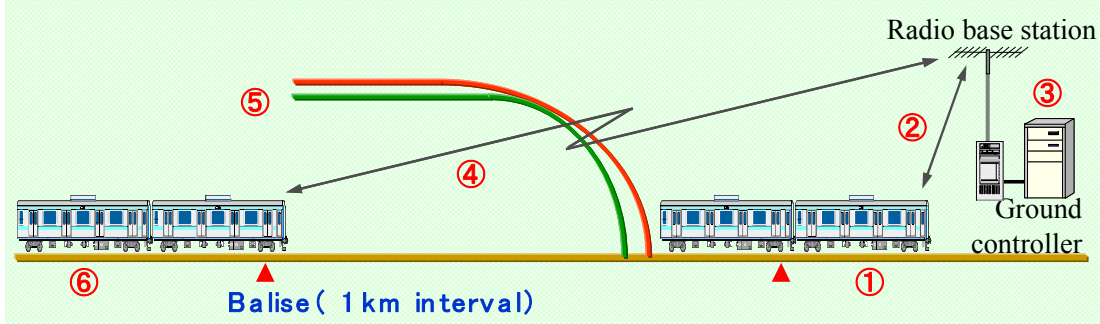

(1) Recognition of train location

(2) Transmission of train location information

(3) Calculation of LMA (Limited Moving Authority)

(4) Transmission of LMA and route information

(5) Calculation of dynamic speed profile

(6) Brake control

Figure 2: Overview of train interval control in ATACS.

1) Efficient train interval control (moving block)

With ATACS, the positions of all trains are detected by onboard devices. The position to which the following train may run (stop limit) is calculated based on the rear point of the preceding train (front end position + train set length), so the 
interval between the preceding train and following train can be efficiently controlled.

2) More efficient test runs using actual cars

ATACS recognizes train position based on a database shared by both wayside and onboard devices. Thus, by connecting the wayside and onboard devices in the factory and using simulated data of a running train, we can reproduce conditions similar to those of an actual running train.

In this way, we can carry out tests with ATACS in the factory to simulate conditions of a running train before test runs using actual trains and actually installed wayside and onboard devices. This improves the efficiency of the actual test runs.

3) Level crossing control by radio

ATACS can control level crossing by radio. And this feature is still being tested.

We will start level crossing control for commercial service by ATACS on Senseki Line in December 2014.

\section{Main components of ATACS}

ATACS is a system whereby running trains themselves detect their own positions and control train operation using interactive radio communications between onboard and wayside devices. It does not depend on train detection using track circuits, a method that has been utilized for more than 100 years.

ATACS is composed of wayside devices, onboard devices, and radio units that perform radio communications between wayside and onboard devices [2]. An overview of each component is as follows (Fig. 3):

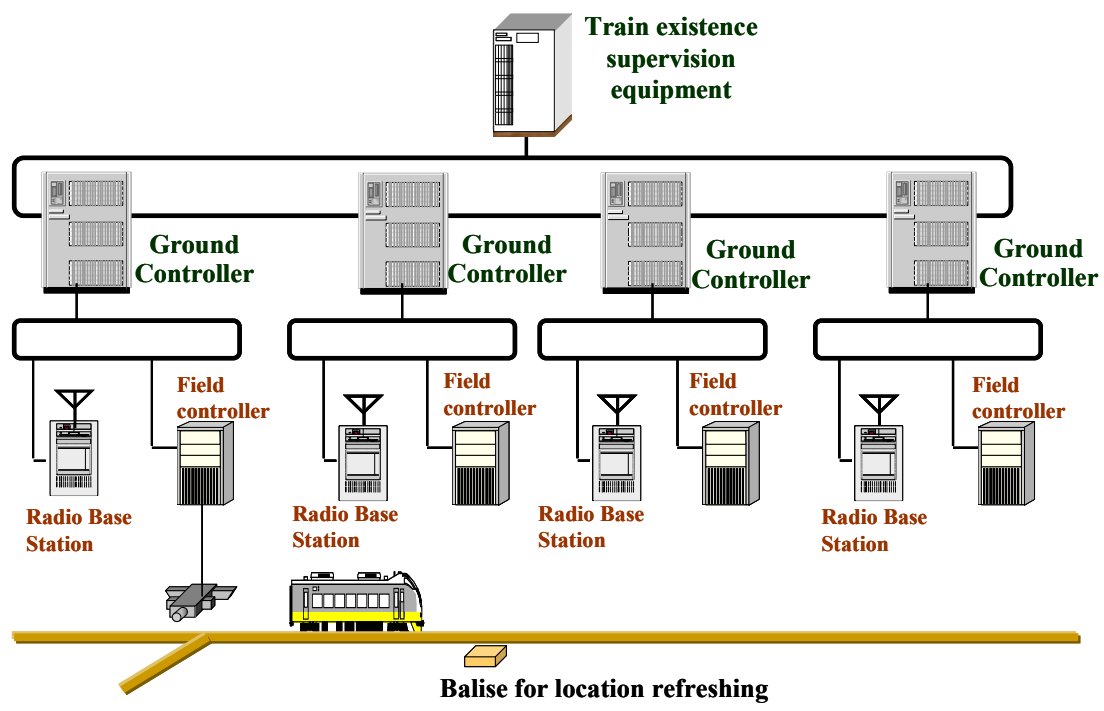

Figure 3: Overview of wayside equipment. 


\subsection{Wayside equipment}

1) Ground controller

The ground controller is the core control equipment of the wayside devices, and has the following functions:

- Identification of train positions based on information from onboard control units

- Route control that creates safe required routes

- Train interval control based on route and train position

- Boundary control whereby entry/exit of trains is controlled at the system boundary

2) Train existence supervision equipment

The train existence supervision equipment manages the IDs of all on-board control devices in the ATACS system, and backs up ground controller in case of system failure.

\section{3) Field controller}

The field controller connects a ground controller with field equipment such as switches, level crossings and radio base stations.

\section{4) Balise for location refreshing}

Installed every kilometer, a balise is a device that transmits train location to onboard controllers so as to enhance onboard controllers' accuracy in train positioning.

\subsection{Onboard equipment}

Onboard equipment for ATACS on the Senseki Line consists of the following incab units, with control units concentrated at the lead car in the direction of AobaDori.

- Onboard controller that controls the train

- In-cab indicator that provides the driver with information

A configuration diagram is shown in Fig. 4 and appearance of onboard equipment shown in Fig. 5.

\section{1) Onboard controller}

The onboard controller is a device with which a train itself detects its position, transmits that position information to ground controllers using a radio unit, receives stop limit information from ground controllers via a radio unit, and creates a braking pattern taking into account track gradient, speed limit and the like to perform speed check and braking control. 


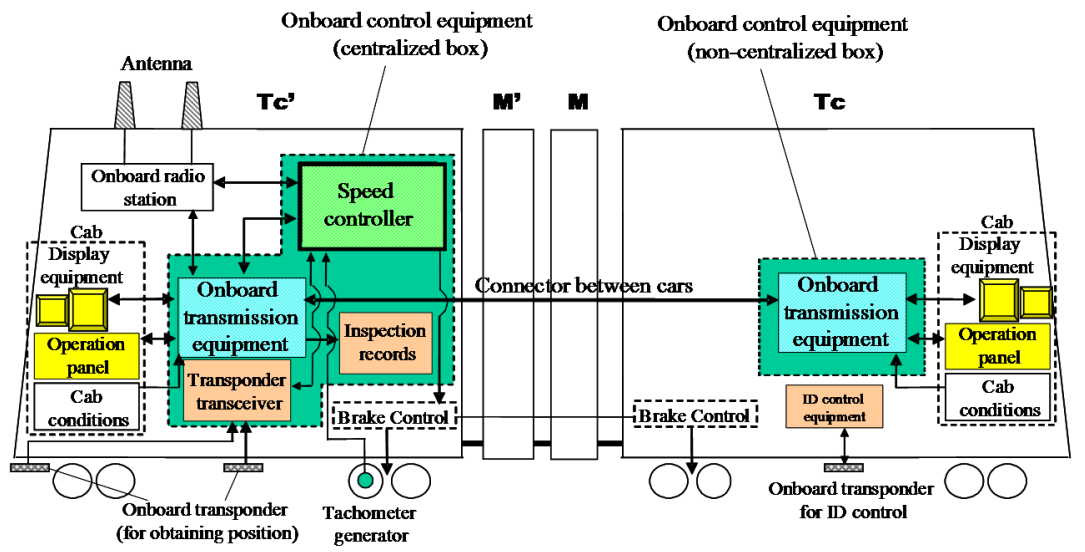

Figure 4: Configuration of onboard equipment.

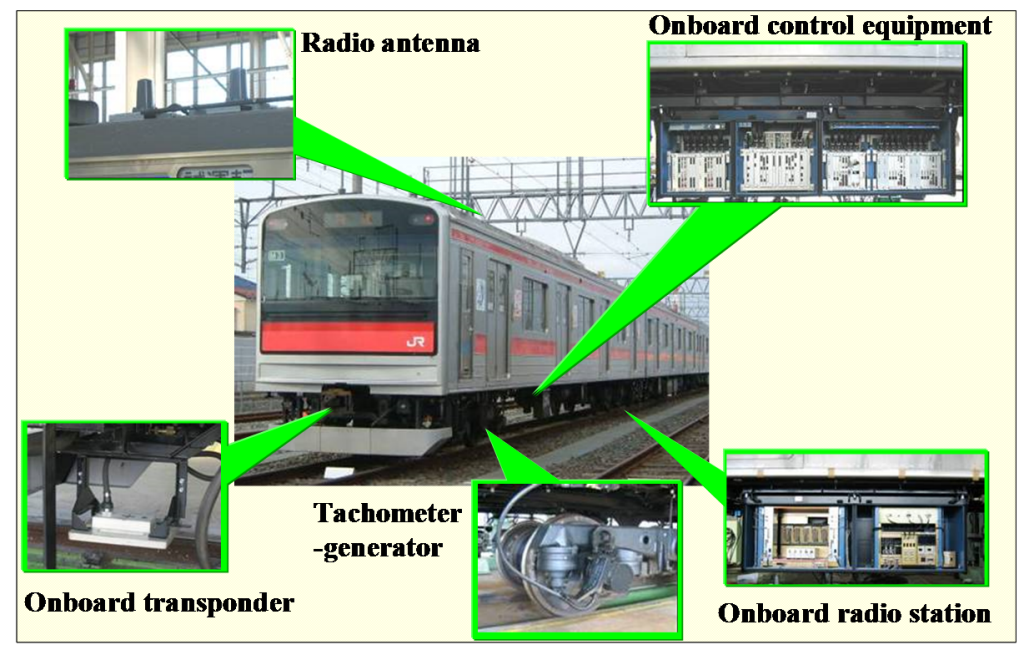

Figure 5: Onboard equipment.

\subsection{Radio system}

The radio system is comprised of the following components, both in duplex for back-up.

- Radio base station (connected to a ground controller)

- Onboard radio station (connected to an onboard controller)

Conforming to the narrow band digital radio standard stipulated by Japan's Radio Law, the radio system basically employs the four-frequency reuse to protect itself from interference between the radio base stations and efficiently use radio signals. The radio base stations are placed at intervals whereby one station controls an area of 2 to $3 \mathrm{~km} \mathrm{[3].}$

An image of their placement is shown in Fig. 6. 


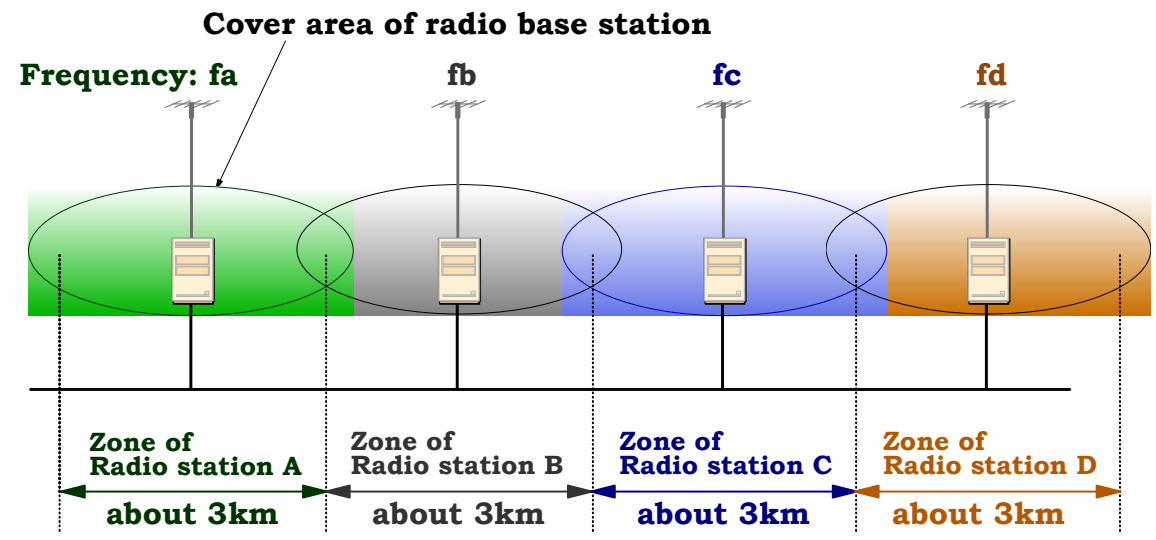

Figure 6: Image of the placement of radio station.

\section{Overview of Senseki Line}

We have been operating ATACS since October 2011 [4]. ATACS has been introduced on a section approximately $18 \mathrm{~km}$ long located between Aobadori Station and Higashi-Shiogama Station on the Senseki Line connecting the cities of Sendai and Ishinomaki in the Tohoku district. There are 14 level crossings and 20 trains. The location of Senseki Line is shown in Figs. 7 and 8.

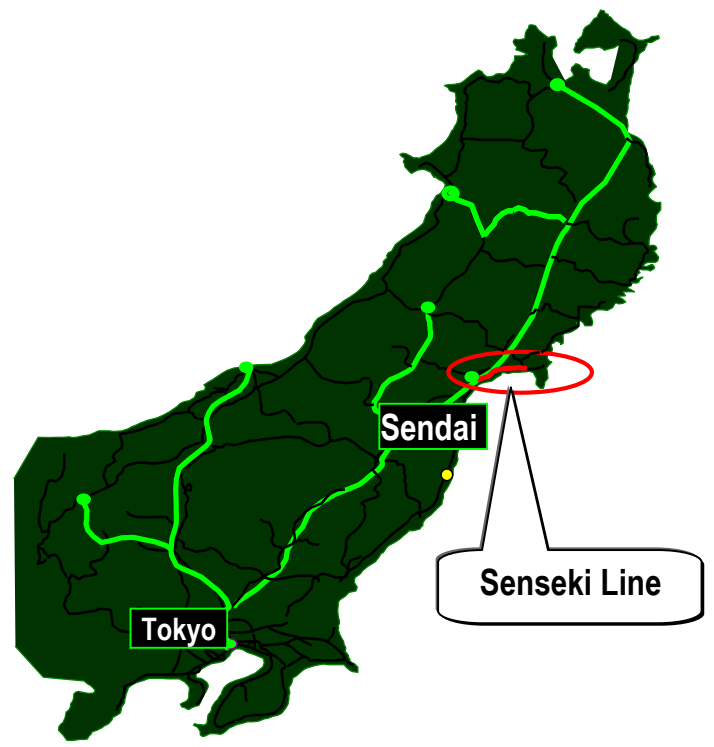

Figure 7: Location of Senseki Line. 
Aobadori Stn. Miyagino Signal Stn.

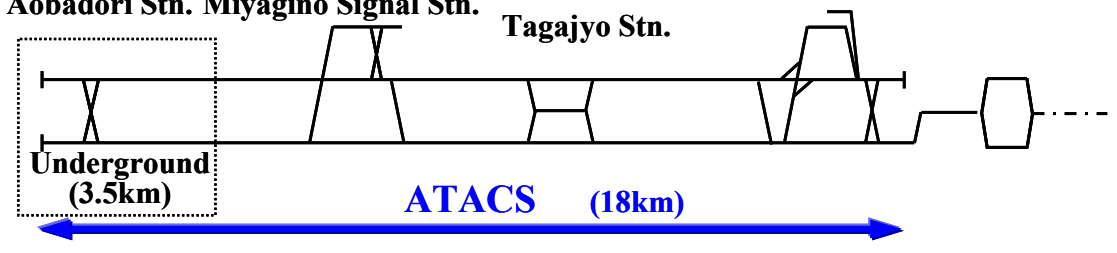

\section{Higashi-Shiogama Stn.}

Figure 8: Location of Senseki Line.

Up to present, the Senseki Line system has been operating with almost no trouble. The system reliability and radio quality of the Senseki Line is shown in Fig. 9. The overall rate of actual operation of ATACS is very high compared with the prognosticated rate. The reliability rate of the ATACS system is $99.99999 \%$. The ATACS system has been out of operation for a total of only 6 seconds.

\begin{tabular}{|l|l|l|l|}
\hline \multicolumn{2}{|c|}{} & Expected & Actual \\
\hline System & Reliability & $99.99 \%$ & $99.99999 \%$ \\
\hline \multirow{2}{*}{$\begin{array}{l}\text { Location } \\
\text { recognition }\end{array}$} & Location refreshing & No error & No error \\
\cline { 2 - 4 } & $\begin{array}{l}\text { System change } \\
\text { (ATACS ATP) }\end{array}$ & No error & No error \\
\hline \multirow{2}{*}{$\begin{array}{l}\text { Radio } \\
\text { Quality }\end{array}$} & Bit error rate & Under $1 \times 10^{-4}$ & Under $1 \times 10^{-7}$ \\
\cline { 2 - 4 } & Frame receiving rate & $99.9 \%$ & $99.9987 \%$ \\
\cline { 2 - 4 } & handover & No error & No error \\
\hline
\end{tabular}

Figure 9: System reliability and radio quality of the Senseki Line.

\section{Plan to introduce ATACS on the Saikyo Line}

We plan to put ATACS into commercial operation on the $26 \mathrm{~km}$ Saikyo Line between Ikebukuro and Omiya in 2017, as the first use of ATACS in the Tokyo metropolitan area. The Saikyo Line is a very important line in the Tokyo metropolitan area. An overview of the Saikyo Line is shown in Fig. 10. 720 thousand travel between Ikebukuro station and Akabane station per day. There are 31 trains, train length 200 meters. 


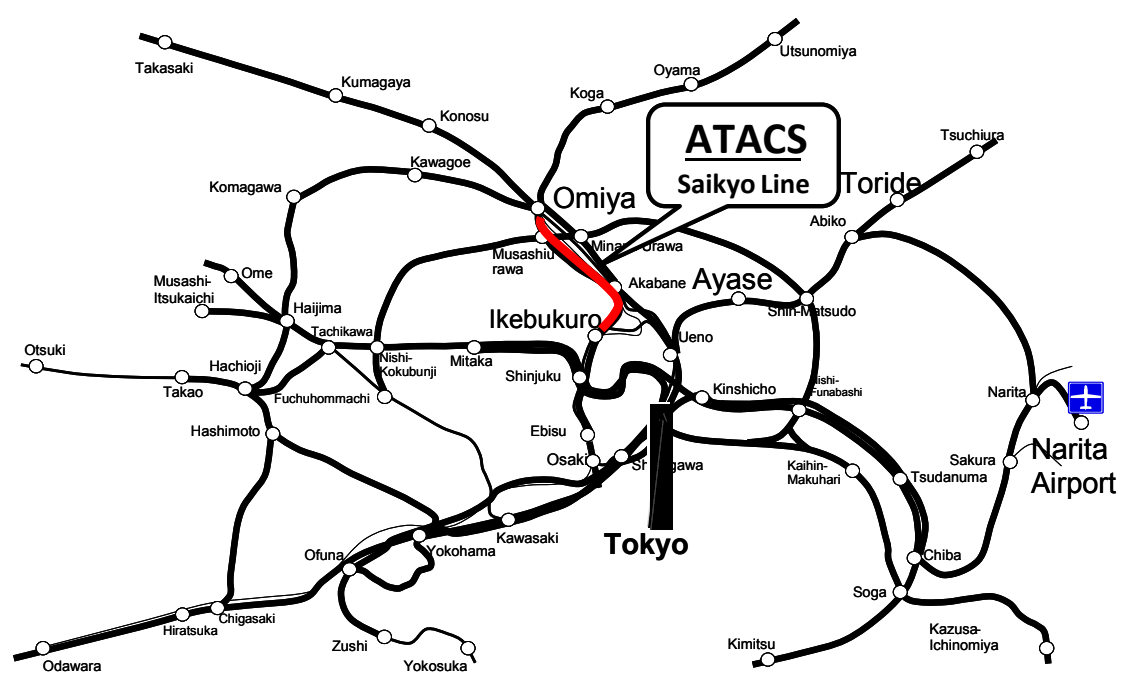

Figure 10: Overview of the Saikyo Line.

\section{Conclusion}

We put ATACS into commercial operation on the Senseki Line in October 2011. We have confirmed ATACS' stability over the last two years, so we are going to introducing ATACS in the Tokyo metropolitan area. We plan to put ATACS into commercial operation on Saikyo Line between Ikebukuro and Omiya in 2017. We hope that ATACS will be widely implemented throughout the metropolitan area. It will result in improved safety, stapler transportation, and lower cost.

\section{References}

[1] Kuroiwa, A.K, Hosaka, H.H, Musen o mochiita ressha seigyo system (ATACS) ni okeru maintenance [in Japanese], JREA, October 2012.

[2] Hiura, N.H, Musen o mochiita ressha seigyo system ATACS no gaiyo [in Japanese], Electrical Installation Engineers of Japan, May 2013.

[3] Kubota, M.K, Musen o mochiita atarashii ressha seigyo system, Senseki sen ATACS [in Japanese], Cybernetics Vol. 17, pp. 5-8, April 2012.

[4] Kuroiwa, A.K, Musen ni yoru ressha seigyo system ATACS no shiyo kaishi [in Japanese], JR gazette Vol. 299, February 2012. 